\title{
Örgütsel Bağlılık ve İş Tatmini Arasındaki İlişki
}

\author{
Bora Yenihan* \\ Sakarya Üniversitesi İ.̇̇.B.F., Sakarya.
}

\section{$\ddot{O} z$}

Örgütsel bağlllık ve iş doyumu arasındaki ilişki kurumlarm başarılarında belirleyici bir rol oynamaktadır. İs doyumu yüksek çalışanlar içinde bulundukları kurumu benimseyerek kendi hedef ve amaçları ile kurumun hedef ve amaçlarım bağdaştıracaklar ve bu sayede kurumun başarısını kendi başarıları gibi göreceklerdir. Bunu sağlayabilen örgütler başarıya doğru ilerlerken, iş görenlerde yaşadıkları iş doyumu sayesinde kendi hedeflerini gerçekleştirebilmek adına daha umutlu olacaklardır. Bunun temel sebebi verimlilik kavraminın emek (insan) ile doğrudan bağlantıl olmasıdır. Teknolojideki gelişmeler ve yeni üretim teknikleri emek faktöründen bağımsız düşünülemez. Örgütler çalışanlarından yeterli verimi alamadıklarn müddetçe diğer üretim faktörleri anlamsız kalacaktır. Verimsiz olan iş görenlerin iş doyum düzeyleri azalacak ve içinde bulundukları örgüte olan bağlllıkları da zayıflayacaktır. Bu durumun beraberinde hem örgüt hem de iş gören için başarısızlı̆̆ı getirmesi kaçınlmazdır. Bunun önüne geçebilmek adına örgütler iş görenlerini yakından takip etmeli ve ihtiyaçlarma cevap verebilmelidir. Bunu başarabilen örgütlerin gelecek kaygısı diğgr örgütlere göre çok daha az olacak ve işletmelerin temel amaçları olan "kâr, büyüme ve süreklilik" ihtiyaçlarını gerçekleştirebileceklerdir.

Anahtar Kelimeler: İş Tatmini, Örgütsel Bağhllık, İşgören, Örgüt

\section{The Relationship Between Organizational Commitment and Job Satisfaction}

\section{Abstract}

The relationship between organizational commitment and job satisfaction plays a decisive role in the success of organizations. Their institutions in higher employee jobsatisfaction by adopting it sgoals and objectives with the organization's goals and objectives will be to reconcile and thus will see the organization's success as their own success. While walking towards the success of organizations that can provide this, employee job satisfaction through their own in order to fulfill the objectives will be more hopeful. The main reason for this, the concept of productivity of labor (human) is directly linked to. Advances in technology and new production techniques considered independent from the labor factor. Organizations of workers did not receive adequate yield will remain meaning less unless other factors of production. Inefficient ones who work in job satisfaction levels will decrease and they will weaken their commitment to the organization. In this case, both the organization as well as work together for the fail bring seeing is inevitable. To counteract this, on behalf of the organizations that work closely monitor and be able to respond to the needs. It concerns the future of the organization can be managed by other organizations and businesses will be much less that the fundamental goals of "profit, growth and sustainability" needs will be able to perform.

Key Words: Job Satsifaction, Organizational Commitment, Employee, Organization 


\section{Giriş}

Son yıllarda örgütsel bağlılık ve iş tatmini kavramlarına olan ilginin artması bu konuda yapılan birçok çalışmayı da beraberinde getirmiştir. Bu kavramların hem birbirleri ile olan etkileşimi hem de diğer örgütsel faktörlerle girdikleri veya girebilecekleri etkileşimler araştırmacıların farklı sektörlerde bu kavramlar üzerine yaptıkları çalışmaları ve çalışmaların sonuçlarını çeşitlendirmektedir. Her ne kadar birbirinden ayrı kavramlar gibi görünseler de hem akademik anlamdaki uygulamalarda hem de organizasyonların içindeki uygulamalarda bu kavramların sıklıkla birlikte ele alındığı yapılan çalışmalardan anlaşılmaktadır. Ayrı ayrı ele alındıkları zaman hem örgütsel bağlılığı ölçmeye yönelik hem de iş tatmin düzeylerini ölçmeye yönelik olarak farklı zamanlarda ve farklı araştırmacılar tarafından çeşitli ölçekler geliştirildiği görülmektedir. Bunun temel sebebi olarak kurumsal anlamda başarı için örgütsel bağlılık ve iş tatmini kavramlarının önem taşımasıdır.

Bu çalışmada öncelikle örgütsel bağlılık ve iş tatmini kavramları ele alınarak farklı araştırmacılar tarafından yapılan tanımlamalar doğrultusunda analiz etmeye çalışılacaktır. Kavramlar incelendikten sonra ise çeşitli yaklaşımlarla örgütsel bağlılık ve iş tatmini arasındaki ilişkiler incelenecek ve birbirlerini hangi düzeyde etkiledikleri ortaya konulmaya çalışılacaktır.

\section{Bağlılık ve Örgütsel Bağlılık Kavramları}

Bağlılık kavramı ele alındığı zaman, eski söyleniş biçimiyle sadakat ve sadık olma durumlarını ifade eder. Toplumsal içgüdünün duygusal bir anlatım biçimi diyebileceğimiz bağl1lık, toplumun ve toplumsal duygunun olduğu her yerde vardır (Balay, 2000: 14). Örgütsel bağlılık kavramının, benzer konularla olan bağlantısı ve farklı araştırma alanlarının örgütsel bağlılık kavramına olan ilgilerinin son yıllarda artması örgütsel bağlllık kavramının tanımlamasını ve anlaşılmasını zorlaştırmaktadır (Gül, 2002: 37-38). Bu yüzden örgütsel bağlılık kavramı literatürde farklı araştırmacılar tarafından farklı şekillerde tanımlanmıştır. Leong ve arkadaşları (1996: 1348) örgütsel bağlılığı, bireylerin belirli kurumlarla girdiği kimliksel birlik ve beraberlik ile bağlılığın birleşimidir şeklinde tanımlar. Davis ve Newstrom'a (1989: 179) göre ise örgütsel bağlılık, kişinin çalıştığı kurum ile kurduğu kimliksel beraberliğin seviyesi ve içinde bulunduğun kurumun aktif bir üyesi olmaya devam etmeyi istemesidir. Balay (2000: 3) ise örgütsel bağlılığı, çalışanın bünyesinde bulunduğu kurumun amaç ve değerlerine taraf olarak etkili bir biçimde bağlanması şeklinde tanımlamaktadır.

Örgütsel bağlllığın artan önemi ve işletmelerin örgütsel bağl1lı̆̆a karşı artan ilgisi araştırmacıları bu konuda çeşitli ölçeklerin geliştirilmeye yöneltmiştir. Mowday ve arkadaşları tarafından 1979 yılında geliştirilen 15 soruluk ölçek yaygın olarak kullanılan bir ölçek olmuştur. Fakat ilerleyen süreçte örgütsel bağlılığ1 tek boyutu ile alan ölçeklerin yetersizliği, çok boyutlu ölçeklerin geliştirilmesi ihtiyacını ortaya çıkarmıştır (Doğan ve Kılıç, 2007: 39-40). Allen ve Meyer (1990: 4) tarafından geliştirilen ölçek ise örgütsel bağlılığı üç boyuta ayırarak incelemektedir. Duygusal bağlllık, devamlılık bağlılığ 1 ve normatif bağlılık alt boyutlarını ortaya koyan Allen ve Meyer 
çalışmalarını bu alt boyutlar çerçevesinde sürdürmüşlerdir (Allen ve Meyer, 1991: 6568).

\section{2. Örgütsel Bağlılı̆̆ın Önemi}

Örgütsel bağlllık ile örgütlerin varlıklarını sürdürebilmeleri arasında önemli bir ilişki vardır. Örgütler, varlıklarının devamı açısından çalışanlarını bünyelerinde tutmayı hedeflerler. Çalışanların örgütsel bağlılıklarının yüksekliği veya düşüklüğü, kurum içinde kalmak ya da ayrılmak konusundaki kararlarında belirleyici etkenlerden bir tanesi olacaktır (Bayram, 2005: 125-126). Örgütsel bağlilığın, kurumlar açısından çok önemli olmasının nedenleri çeşitli kavramlarla etkileşim içinde olmasından kaynaklanır. Bu kavramlar, işten ayrılma, devamsızlıkların artması, geri çekilme ve iş arama faaliyetleri, iş tatmini, işe sarılma, moral ve performans gibi tutumsal, duygusal ve bilişsel yapılar, bağımsızlık, sorumluluk, katılım, görev anlayışı gibi işgörenin işi ve rolüne ilişkin özellikler, yaş, cinsiyet, hizmet süresi ve eğitim gibi işgörenlerin kişisel özellikleri olarak siralanabilir (Balay, 2000: 1-2).

\section{3. Örgütsel Bağlılığın Sınıflandırılması ve Boyutları}

Örgütsel bağlılı̆̆ın sınıflandırılması konusunda literatürde birbirinden farklı yaklaşımlar bulunmaktadır. Bu yaklaşımlar, Kanter (1968) yaklaşımı, O'Reilly ve Chatman (1986) yaklaşımı, Etzioni yaklaşımı, Penley ve Gould (1988) yaklaşımı ile Allen ve Meyer (1990) yaklaşımlarıdır (Gül, 2002: 42-45). Fakat literatürde en çok kabul gören ve en fazla temel alınan sinıflandırma Allen ve Meyer tarafından 1990 yılında yapılan sınıflandırmadır (Doğan ve Kılıç, 2007: 44). Allen ve Meyer örgütsel bağlılığı kendi içerisinde şekil 1'de görülebileceği gibi üç farklı alt boyuta ayırmıştır (Meyer ve Diğ., 2002: 36).

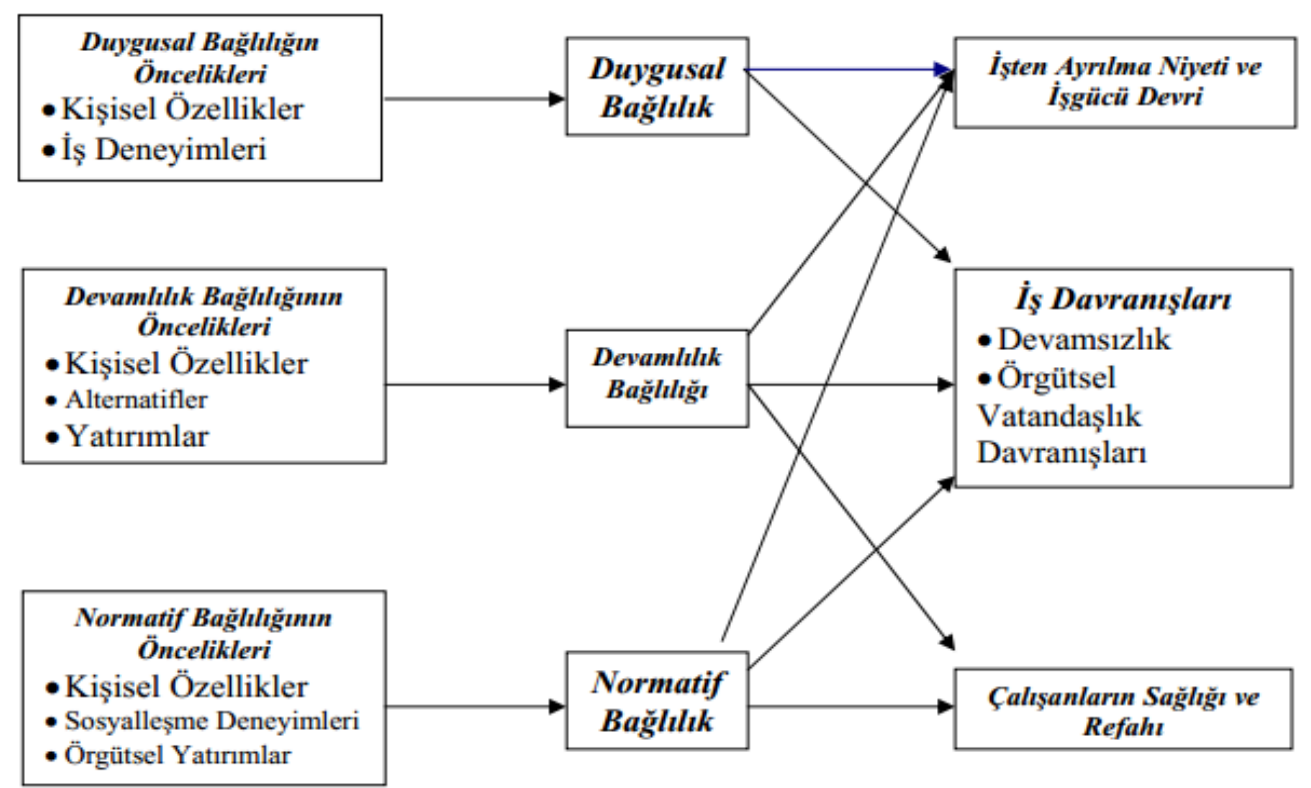

Şekil 1. Allen ve Meyer Tarafından Yapılan Örgütsel Bağlılık Sınıflandırmasının Alt Boyutlar1

Kaynak: Meyer ve Diğ., 2002: 36 


\section{a. Duygusal Bağlılık}

Duygusal bağl1lık literatürde tutumsal bağlılık şeklinde de ifade edilmekte olup, çalışanların mensubu oldukları işletmelerin, kurum ve kuruluşların hedeflerini, amaçlarını ve öz değerlerini benimsedikleri seviye ve doğrultuda görülen bağlılıktır (Bayram, 2005: 132, Doğan ve Kılıç, 2007: 44). Wiener (1982: 424) yaptığ1 çalışmada duygusal bağl1lığ1 "Işgören, kurumun değerleriyle kendi inandığı değerlerin örtüştüğünü gördü̆̆̈̈ durumda duygusal olarak içinde bulunduğu kuruma bă̆lanmaktadır" şeklinde bir tanımlama yapmıştır.

Çalışanın, içinde bulunduğu organizasyona yönelik olarak hissettiği duygusal bağlılık, çalışan ile organizasyonu arasındaki karşılıklı bütünleşmeyi ortaya koyar. Duygusal bağlılığı güçlü olan çalışanların en önemli özelliği ihtiyaçları olduğu için değil, bunu istedikleri için kurumda kalmaya devam etmeleridir (Zangaro, 2001: 15).

\section{b. Devamlılık Bağlılığı}

Bu bağlılık türünün bir diğer adı da "Rasyonel Bağlılıktır". Temelde çalışanın kurumdan ayrılması halinde karşılaşacağı ve katlanması gereken maliyeti konu edinir. Diğer bir bakış açısıyla İşgören kurumdan ayrılmanın maliyetlerinin yüksek olacağı endişesiyle çalışmaya devam eder (Allen ve Meyer, 1990: 67, Lamsa ve Savolainen, 1999: 36).

Devamlılık bağlılığı daha çok işgörenin kıdem, kariyer gibi yatırımları ile ilgilidir. Çalışan bu konularda içinde bulunduğu kurumda kendisine yaptığ yatırımların yüksek olduğunu düşünüyorsa devamlılık bağlılı̆̆1 da yüksek olacaktır (Gül, 2002: 45, Doğan ve Kılıç, 2007: 46).

\section{c. Normatif Bağlılık}

Zorunlu bağlılık ya da kuralcı bağlılık olarak da adlandırılan normatif bağlılık, çalışanın kurumda kalmaya devam etmek ile ilgili olarak hissettiği zorunluluk duygusunu yansıtmaktadır (Doğan ve Kılıç, 2007: 47, Demirel, 2009: 117).

Normatif bağlılı̆̆ın söz konusu olduğu durumlarda İşgören, kurumda çalışmayı kendisi için bir görev olarak kabul eder ve bağlılık hissinin doğru olduğunu düşünür. Bu bağlılık türünde devamlılık bağlılığında olduğu gibi işten ayrılmasının işgörenin kendisine yükleyeceği maliyetler önemlidir. İşgörenin minnettarlık duygusu ön plandadır (Çetin, 2004: 91).

\section{4. İş Tatmini Kavramı ve Önemi}

Günümüzde iş yaşamı, insanların yaşamının çok önemli bir parçasını oluşturmaktadır (Telman ve Ünsal, 2004: 12). Bu bakış açısıyla ele alındığ1 zaman iş tatmini insanların yaşamı ve mutluluğu için çok önemlidir (Yiğit ve Diğ., 2011: 4). Tanım olarak iş tatmini genel anlamda işgörenin yaptığı iş karşılığında hissettiği manevi tatmindir fakat literatür incelendiğinde birbirinden farklı tanımlarla karşılaşılmaktadır (Aşık, 2010: 34). İş tatmini, insanların duygularıyla yaptıkları iş arasındaki ilişkiyi yansıtır. Spector (1996: 6-7) iş tatminini "en basit haliyle insanlarm işinden hoşlanma derecesidir" şeklinde tanımlamaktadır. Barutçugil ise (2004: 389) iş 
tatminini "bir işgörenin çalıştı̆̆ işten ve elde ettiklerinin ihtiyaç duyduklar ve kişisel değer yargılarıyla örtüştüğ̈̈̈nü ya da örtüşmesine olanak sağladığııı fark etmesi sonucu yaşadığı bir duygu" şeklinde tanımlamaktadır.

İş tatminin yönetimsel anlamda üzerinde çok durulan bir konu olmasının sebebi, yapılan iş ile ilgili olarak elde edilebilecek olumlu sonuçların büyük ölçüde işgörenin iş tatmininin sağlanmasıyla doğru orantılı olmasıdır (Yousef, 1997: 184). İş tatmininin yüksek olduğu durumlarda, verimlilik yüksek olacak, işten ayrılmalar ve devamsızlık azalacak diğer yandan ise örgütsel bağlılık artacaktır (Aşık, 2010: 35). Luthans'a (1995: 3-4) göre iş tatmini beraberinde üç tane önemli noktayı ortaya çıkarır:

- İş tatmini ağırlıklı olarak duygusal bir kavramdır. Bunun sebebi hissedilebilmesi fakat somut olmamasıdır.

- İş tatmini, iş çıktıları ile beklentiler arasındaki uyum ve örtüşmeyi ifade eder.

- İş tatmini, birbiri ile alakalı birçok kavramı da ortaya koyar. Bu kavramlar genellikle ücretler, yükselme imkânları, yapılan iş, iş arkadaşları gibi kavramlardir.

İş tatmini, yapısı gereği dinamik bir algıdır. Kurumlar çalışanlarının iş tatminleri sağladıktan sonra bunu bir süre gözden uzak tutamazlar. Çünkü iş tatmini ne kadar hızlı sağlanabiliyorsa bir o kadar da hızla kaybedilebilir. Kurumlarda çalışma koşullarının bozulduğunun ve istenen seviyeden uzaklaştığının önemli göstergelerinden bir tanesi iş tatminsizliğidir ya da iş tatmininin düşük olmasıdır. İş tatminsizliği, işgörenin işinden keyif alma duygusunu kaybetmesi, hoşlanmaması şeklinde ifade edilebilir. İş tatminsizliği daha üstü örtülü şekillerde kendisini iş yavaşlatma, verimsizlik veya olması gerekenden daha düşük verim, disiplinsizlik şeklinde kendisini gösterebilir (Aş1k, 2010: 35-36).

\section{5. İş Tatmini ve Örgütsel Bağlılık Arasındaki İlişki}

Özellikle örgütsel bağlılık ile ilgili olarak yapılan çalışmalarda iş tatmini ile örgütsel bağlılık arasında doğru orantılı bir ilişki olduğu ortaya konmaktadır (Tekingündüz ve Tengilimoğlu, 2013: 80). Bennet ve Durkin (2000) tarafından yapılan çalışmada, iş tatmini ve örgütsel bağlılık arasında doğru orantılı, pozitif bir ilişki bulunmuştur (Akt. Culverson, 2002: 30). Çelen ve arkadaşları (2013: 406-407) tarafından Gülhane Askeri Tıp Fakültesi Eğitim Hastanesinde yapılan araştırma da duygusal ve normatif bağl1lı̆̆ 1 yüksek olan işgörenlerin iş tatmin düzeylerinin de yüksek olduğu, devamlılık bağlılığı ile iş tatmini arasında ise bir ilişki olmadığı ortaya konmuştur. Top (2012: 272-273) tarafından hekim ve hemşirelerin örgütsel bağlllık, örgütsel güven ve iş tatmini ilişkisini ölçmeye yönelik yapılan çalışmada ise örgütsel bağlılık ve iş tatmini arasında anlamlı ve pozitif bir ilişki bulunmuş, sadece normatif bağlılık ile iş tatmini arasında anlamlı bir ilişki tespit edilememiştir. Sığrı ve Basım (2004: 147-150) tarafından yapılan araştırmada ise iş tatmini ve örgütsel bağlılık arasında anlamlı ve pozitif bir ilişki olduğu ortaya konmuştur. Sığrı ve Basım’a göre iş tatmin seviyesinde meydana gelecek bir artış örgütsel bağlılı̆̆ı arttırırken, iş tatmin seviyesinde meydan gelecek bir azalma da örgütsel bağlılığı azaltacaktır. 
Örgütsel bağlllık ve iş tatmini birlikte incelendiği zaman, işgörenin hem iş yerine hem de yapmakta olduğu işe karşı geliştirdiği duygu ve düşüncelerin bütünü şeklinde ifade edilebilir. İş tatmini, işgörenin hali hazırda yapmakta olduğu işi ile ilgili duygu ve düşünceleriyle ilgiliyken, örgütsel bağlllık işgörenin hali hazırda çalışmakta olduğu kuruma karşı duygu ve düşünceleriyle ilgilenir (Çetinkanat, 2002: 2-3).

\section{a. İş Tatmini Örgütsel Bağlılığa Neden Olur}

Mousday ve arkadaşları tarafından (1980) yapılan araştırma, iş tatmininin kişisel ve kurumsal faktörlerden etkilenen bir alg1 olduğunu ortaya koymuştur. Buradan hareketle Mousday ve arkadaşları örgütsel bağlılı̆̆ında aynı ve benzer faktörlerden etkilenebileceğini söylemektedir. Aradaki fark ise iş tatmini, bu ve benzeri faktörler için hızlı ve duygusal cevaplar geliştirebilirken, örgütsel bağlılık daha yavaş gelişen bir süreçtir. Ayrıca örgütsel bağlılık sürecinde kurumun hedefleri ve değerleri, çalışandan performans beklentisi ve sonuçları gibi faktörlerde etkilidir (Akt. Vandenberg ve Scarpello, 1994: 535-537). Karataş ve Güleş (2010: 86-87) tarafından yapılan araştırmada ortaya çıkan sonuçlara göre de iş tatmini ve örgütsel bağlılık karşılıklı olarak etkileşim içindedir ve iş tatmini yüksek olan işgörenlerin örgütsel bağlılığının da yüksek olacağı, tam tersi durumlarda ise iş tatmini ile paralel olarak örgütsel bağlılığında azalacağı ortaya konulmuştur.

\section{b. Örgütsel Bağlılık İş Tatminine Neden Olur}

İş tatmininin örgütsel bağlılığa sebep olduğunu belirten çalışmaların yanında, örgütsel bağlllı̆̆ın da iş tatminine sebep olduğunu destekleyen görüşler de bulunmaktadır. Örgütsel bağlılık, çalışma ortamının etrafında olumlu ve duygusal bir tepki olarak görülebilir. Çalışanların içinde bulundukları kurumun hedeflerine, amaçlarına ve değerlerine olan inançlarının çok kuvvetli olduğu durumlarda ya da kurum içinde kalma istek ve hedeflerinin çok güçlü olduğu durumlarda ortaya çıkar. $\mathrm{Bu}$ ve benzeri durumlarda örgütsel bağlılık düzeylerinde meydana gelecek artışlar duygusal bir tepki şeklinde iş tatmin düzeylerini de arttırabilecektir (Örücü ve Diğ., 2010: 5).

\section{c. Örgütsel Bağlılık ve İş Tatmini Birbirlerine Neden Olur}

İş tatmini ve örgütsel bağlllık kavramları, iş ile ilgili tutum, duygu ve düşünceleri inceleyen çalışmalara sıklıkla konu olurlar. Literatür incelendiği zaman bazı araştırmacılar bu iki kavram arasında karşılıklı bir sebep-sonuç ilişkisi olduğunu belirtirler. Bu iki kavram arasında bulunan sebep-sonuç ilişkilerinin bir bölümü hala belirsiz olmakla birlikte, iş tatmininin ve örgütsel bağlılığın değişen amaçlar, işin niteliği ve büyüklüğü, performans, devamsızlık gibi örgütsel sonuçları etkileme gücüne sahip birbirileriyle ilişkili değişkenler oldukları söylenebilir (Testa, 2001: 228).

\section{d. Örgütsel Bağlılık ve İş Tatmini Arasında İlişki Yoktur}

Mowday, Porter ve Steer tarafından 1982 yılında yapılan çalışmada iş tatmini ve kurumsal bağlılık arasındaki en temel farklılık olarak, örgütsel bağlılık kuruma karşı çalışanların geliştirdiği duygusal tepkilerken, iş tatmininin ise kurumadan ziyade çalışanın belirli bir işe karşı geliştirdiği duygusal tepkiler olarak ortaya konmuştur. Bu 
iki kavramında birbiri ile sebep-sonuç çerçevesinde yüksek derecede ilişkili olduğu düşünülürken ve beklenirken, çalışan içinde bulunduğu kuruma karşı bağlllık anlamında pozitif ve güçlü duygulara sahipken, yaptığı işten dolayı mutlu olmayabilir. İşgörenin iş tatmin düzeyi ile örgütsel bağlılık düzeyi arasında her zaman bir ilişki olmayacağı göz ardı edilmemelidir (Örücü ve Diğ., 2010: 5).

\section{Sonuç ve Tartışma}

Literatür incelendiği zaman hem örgütsel bağlllık hem de iş tatmini üzerine yapılmış çok sayıda çalışma olduğu görülmektedir. Birçok çalışma ve araştırmacı örgütsel bağlılık ve iş tatmini kavramlarının birbirleri ile olan ilişkilerini ve kurum içindeki diğer faktörlerle olan ilişki ve bu faktörlere olan etkilerini incelemiştir. İşgörenlerin bireysel anlamda hedeflerine ulaşma ve başarılı olmalarının yanı sıra organizasyonların kurumsal amaç ve hedeflerine ulaşarak başarılı olmaları için de iş tatmini ve örgütsel bağlılık önem taşımaktadır. Bu iki kavramın kurum içindeki birçok değişkenle etkileşim içine girebilmesine rağmen birbirleri ile olan güçlü etkileşimleri ön plana çıkmaktadır. Yurt dışında ve ülkemizde yapılan birçok çalışma göstermektedir ki iş tatmin düzeylerinin yüksek olması örgütsel bağlılık düzeylerini de olumlu yönde etkilemekte ve bununla bağlantılı olarak başarı adına diğer kurum içi faktörlerde olumlu etkilenmektedir.

Yapılan araştırmalar iş tatmini ve örgütsel bağlılık arasında sebep-sonuç ilişkisine dayalı karşılıklı bir etkileşim olduğunu ortaya koymakla birlikte alan yazımdaki bulguların ve görüşlerin önemli bir bölümü iş tatmininin örgütsel bağlılığı olumlu ya da olumsuz etkileme gücüne daha çok sahip olduğunu belirtmektedir. Bu açıdan bakıldığında çalışanların iş tatmini düzeyleri ön plana çıkmaktadır. Örgütsel bağlılığın arttırılması ve çalışanların kurum içinde tutulabilmesi için iş tatmini organizasyonlar adına önemli bir amaç ve araç olarak görülebilir. Çalışanlarının iş tatmin düzeylerini arttırabilen ve koruyabilen kurumlar için çalışanlarını kurum içinde tutmak bunu sağlayamayan kurumlara kıyasla daha kolay olacaktır.

Bir başka bakış açısıyla, organizasyonların işgörenlerin iş tatmin düzeylerini arttırmaları önem taşımaktadır. Örgütsel bağlılığın oluşturulması aşamasında izlenecek stratejiler belirlenirken işgörenlerin iş tatmin düzeyleri mutlaka göz önüne alınmalı ve bu doğrultuda bir plan yapılmalıdır. İşgörenlerin iş tatmin düzeylerinin arttırıldığı oranda kurumsal bağlılık seviyelerinin de arttırılabileceği gözden kaçırılmamalıdır.

Çalışanlarının istek ve ihtiyaçlarına dikkat eden, çalışma ortamı ve yapılan iş konusunda çalışanları ile sürekli irtibatta olan ve fikir alış-verişinde bulunan kurumlarda çalışan işgörenlerin iş tatmin düzeyleri yüksek olacaktır. İş tatmin seviyelerin yüksekliği ise arasında sebep-sonuç ilişkisi bulunan örgütsel bağlılık seviyelerini-ki özellikle normatif ve duygusal bağlılık seviyelerini-yükseltecek ve kurumların başarılı çalışanlarını bünyelerinde tutmalarını kolaylaştıracaktır. Bu durum ilerleyen süreçte beraberinde kurumsal başarıyı getiren etkenlerden birisi olabilecektir. 
Her ne kadar yapılan birçok çalışma iş tatmininin, örgütsel bağlllık üzerinde olumlu veya olumsuz etkileri olduğunu ortaya koysa da, bu iki kavram arasında bir sebep-sonuç ilişkisi olduğu gözden kaçırılmamalıdır. Çeşitli araçlarla işgörenlerin iş tatmin düzeyleri yükseltilemediği zaman sebep-sonuç ilişkisi ile örgütsel bağlllık seviyeleri arttırılarak, iş tatmin düzeylerini arttırmak mümkün olabilir.

\section{Kaynakça}

Allen, N. ve Meyer, J. (1990). The Measurement and Antecedents of Affective, Continuance and Normative Commitment to the Organization. Journal of Occupational Psychology, Vol. 63.

Aşık, A. Nuran. (2010). Çalışanların İş Doyumunu Etkileyen Bireysel ve Örgütsel Faktörler İle Sonuçlarına İlişkin Kavramsal Bir Değerlendirme. Türk İdare Dergisi, Sayı 467, Haziran.

Balay, R. (2000). Yönetici ve Öğretmenlerde Örgütsel Bağhllık. Ankara: Nobel Yayın Dağıtım Ltd. Şti.

Barutçugil, İ. (2004). Stratejik İnsan Kaynakları Yönetimi. İstanbul: Kariyer Yayıncılık.

Bayram, L. (2005). Yönetimde Yeni Bir Paradigma: Örgütsel Bağlllık. Sayıştay Dergisi, Sayı 59, Ekim-Aralık.

Culverson, D. and Elizabeth (2002). Exploring Organizational Commitment Following Radical Change: A Case Study within the Parks Canada Agency. Ontario: University of Waterloo, MA Thesis.

Çelen, Ö., Teke, A. ve Cihangiroğlu, N. (2013). Örgütsel Bağlılığın İş Tatmini Üzerine Etkisi: Gülhane Askeri Tip Fakültesi Eğitim Hastanesinde Bir Araştırma. Süleyman Demirel Üniversitesi, İ.I.B.F. Dergisi, Cilt 18, Sayı 3, Isparta.

Çetin, M. Ö. (2004). Örgüt Kültürü ve Örgütsel Bă̆lllık. Ankara: Nobel Yayın Dağıtım.

Çetinkanat, C. (2000). Örgütlerde Güdüleme ve İş Doyumu. Ankara: Anı Yayıncılık.

Davis, K. and Newstrom, J. (1989). Human Behavior at Work, Organizational Behavior. Eight Edition, McGraw Hill Book Company, New York.

Demirel, Y. (2009). Örgütsel Bağlılık ve Üretkenlik Karşıtı Davranışlar Arasındaki İlişkiye Kavramsal Yaklaşım. İstanbul Ticaret Üniversitesi, Sosyal bilimler Dergisi, Yıl 8, Sayı 15, Bahar.

Doğan, S. ve Kılıç, S. (2007). Örgütsel Bağllı̆ı̆ıın Sağlanmasında Personel Güçlendirmenin Yeri ve Önemi. Erciyes Üniversitesi, İI.̇.B.F. Dergisi, Sayı 29, Temmuz-Aralık.

Gül, H. (2002). Örgütsel Bağlılık Yaklaşımlarının Mukayesesi ve Değerlendirmesi. Ege Akademik Bakış, Cilt 2, Sayı 1.

Karakaş, S. ve Güleş, H. (2010). İlköğretim Okulu Öğretmenlerinin İş Tatmini ile Örgütsel Bağl1lığı Arasındaki İlişki. Uşak Üniversitesi, Sosyal Bilimler Dergisi, 3/2, Uşak.

Lamsa, A. M. and Savolanien, T. (2000). The Nature Of Managerial Commitment To Strategic Change. Leadership \& Organization Development Journal, Vol 21-6.

Leong, C., Furnham, A. and Cooper, C. (1996). The Moderating Effect of Organizational Commitment on the Occupational Stress Outcome Relationship. Human Relations, Vol 49-10.

Luthans, F. (1995). Organizational Behavior. McGraw-Hill, Inc., New York. 
Meyer, J. and Allen, N. (1991). A Three-Component Conceptualization of Organizational Commitment. Human Resource Management Review, Vol. 1-1.

Meyer, J., Stanley, D. J., Herscovitch, P. and Topolnytsky, L. (2002). Affective, Continuance, and Normative Commitment to the Organization: A Meta-analysis of Antecedents, Correlates, and Consequences. Journal of Vocational Behavior, Vol 61.

Örücü, E., Kılıç, R. ve Şimşir, S. (2010). Organizasyonlarda İş Tatmini Uygulamaları ve Örgütsel Bağllığa Etkisi Üzerine Bir Araştırma. Balıkesir Üniversitesi, Bandırma İ.İ.B.F. Yönetim ve Ekonomi Araştırmaları Dergisi, Sayı 13, Balıkesir.

Spector, P. (1996). Industrial and Organizational Psychology: Research and Practice USA. John Wiley \& Sons Inc.

Sığrı, Ü., Basım, N. (2004). İşgörenlerin İş Doyum ve Örgütsel Bağlılık Düzeylerinin Analizi: Kamu ve Özel Sektörde Karşılaştırmalı Bir Araştırma. Selçuk Üniversitesi, Sosyal ve Ekonomik Araştırmalar Dergisi, Konya.

Tekingündüz, S. ve Tengilimoğlu, D. (2013). Hastane Çalışanlarının İş Tatmini, Örgütsel Bağlılık ve Örgütsel Güven Düzeylerinin Belirlenmesi. Sayıştay Dergisi, Sayı 91, EkimAralık.

Telman, N. ve Ünsal, P. (2004). Çalışan Memnuniyeti. İstanbul: Epsilon Yayınevi.

Testa, M. R. (2001). Organizational Commitment, Job Satisfaction, and Effort in the Service Environment. The Journal of Psychology, 135-2.

Top, M. (2012). Hekim ve Hemşirelerde Örgütsel Bağlllık, Örgütsel Güven ve İş Doyumu Profili. İstanbul Üniversitesi, İşletme Fakültesi Dergisi, Cilt 41, Sayı 2, İstanbul.

Yiğit, R., Dilmaç, B. ve Deniz, E. (2011). İş ve Yaşam Doyumu: Konya Emniyet Müdürlüğü Alan Araştırması. Polis Bilimleri Dergisi, Cilt 13-3.

Vandenberg, R. ve Scarpello, V. (1994). A Longitudinal Asswssment of the Determinant Relationship Between Employee Commitments to the Occupation and the Organization. Journal of Organizational Behavior, Vol 15.

Wiener, Y. (1982). Commitment in Organization a Normative View. Academy of Management Review, 7-3.

Yousef, D. (1998). Satisfaction with Job Security As a Predictor of Organizational, Commitment and Job Performance in a Multicultural Environment. International Journal of Manpower, 19.

Zangaro, G. (2001). Organizational Commitment: A Concept Analysis. Nursing Forum, Vol: 36, No: 2, April-June. 